\title{
ХАРАКТЕРНЫЕ ПРОЯВЛЕНИЯ ВЕНОЗНОЙ ДИСЦИРКУЛЯЦИИ У ДЕТЕЙ И ПОДРОСТКОВ С АРТЕРИАЛЬНОЙ ГИПЕРТОНИЕЙ
}

\author{
Алиджанова Д.А., Маджидова Ё.Н.*, Турсунхужаева С.Ш. \\ Ташкентский педиатрический медицинский институт, Ташкент, Узбекистан
}

В основу данной статьи положены данные обследования 82 подростков с артериальной гипертонией. Возраст об-

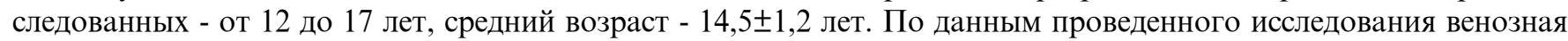
дисциркуляция головного мозга при артериальной гипертонии у подростков характеризуется определенным клиническим симптомо-комплексом. Наличие симптомов, свидетельствующих о церебральной венозной недостаточности, позволяет уточнить диагноз и степень заболевания и назначить патогенетически обоснованную терапию. Ключевые слова: венозная дисциркуляция, артериальная гипертония, подростки, диагностика.

Проблема профилактики и лечения АГ у детей и подростков занимает приоритетное положение в детской кардиологии [12]. Это связано с высокой распространенностью АГ, регистрируемой у 8-25\% школьников, а также с возможностью трансформации АГ в ишемическую и гипертоническую болезни, являющиеся основной причиной инвалидизации и смертности взрослого населения. Важно подчеркнуть, что профилактика и лечение АГ в детском возрасте являются более эффективными по сравнению с взрослым контингентом больных $[5,8]$.

Развитие и прогрессирование АГ, несомненно, связано с особенностями характеристик АД, в том числе и различных параметров его суточных вариаций [9]. Кроме того, показано, что поражение головного мозга при АГ тесно связано не только с повышенным уровнем АД, но и особенностями циркадного ритма, в частности с величиной суточного индекca $[1,4,11]$.

Несмотря на то, что структура сердечнососудистых заболеваний и основные патологические состояния, послужившие причиной смерти у детей и взрослых, различны, очевидно, что формирование так называемых взрослых типов патологии начинается именно в детском возрасте. Поздняя диагностика и неадекватная оценка прогноза у детей лежат в основе высокой заболеваемости и смертности в старших возрастных группах, а успех профилактических программ напрямую зависит от их ранней реализации [4]. Гипертоническая и ишемическая болезни сердца, нарушения ритма, кардиомиопатии и даже атерос- клероз нередко начинаются в детстве, прогрессируют и часто становятся причиной нетрудоспособности в более старшем возрасте. Положительный опыт стран с низким уровнем смертности от сердечно-сосудистых заболеваний показывает, что на успешность борьбы с этой патологией огромное влияние оказывают ее раннее выявление, лечение и профилактика в детстве [6, 10, 13].

В научной литературе мало указаний на возможную связь неврологической сосудистой синдроматики с суточным профилем АД и состоянием церебрального артериального и венозного кровообращения у подростков $[3,7]$.

Цель исследования: изучить особенности клинико-неврологических проявлений венозной дисцеркуляции у детей и подростков с артериальной гипертонией.

Материалы и методы исследования: Работа основана на результатах обследования и изучения 82 подростков с АГ. Возраст обследованных - от 12 до 17 лет, средний возраст $14,5 \pm 1,33$ лет. Всего было 59 мальчиков $(72,0 \%)$ и 23 девочки $(28,0 \%)$. Полученные данные обследования детей с АГ сравнивали с результатами в контрольной группе (30 детей).

Всем обследованным были проведены стандартные клинико-неврологические обследования.

Клиническая симптоматика больных соответствовала АГ І ст. и АГ ІІ ст. с учетом классификации и второго пересмотра рекомендаций 2003 года, разработанных группой экспертов Всероссийского научного общества кардиологов (ВНОК), рекомендаций Европейского общества по артериальной гипер-

*e-mail:madjidova1@yandex.ru 
тензии и Европейского общества кардиологов 2007 года [6].

Измерение АД проводилось в строгом соответствии с требованиями общепринятой методики согласно рекомендациям ВОЗ/МОАГ 1999, ДАД. В ходе обследования исключали симптоматический характер АГ.

Клиническая симптоматика соответствовала АГ І ст. у 45,1\% (37 детей) и АГ II ст. у 54,9\% (45 детей) больных.

Для изучения показателей венозной дисциркуляции всем больным были проведены ультразвуковые допплерографические исследования. Изучались показатели: V max - максимальная линейная скорость кровотока; V min - минимальная линейная скорость кровотока; V mean - средняя линейная скорость кровотока; V об. max - максимальная объемная скорость кровотока; V об. min - минимальная объемная скорость кровотока; V об. ср. - средняя объемная скорость кровотока; IR - индекс резистентности; PI - пульсационный индекс.

Результаты исследования: Клиническая симптоматика соответствовала АГ I ст. у $45,1 \%$ (37 пациентов) и АГ ІІ ст. у 54,9\% больных (45 пациентов). Одной из самых распространенных жалоб при АГ у подростков была головная боль $(62,2 \%)$. Наиболее частыми "венозными жалобами" у детей с АГ были симптом "тугого воротничка" (34,1\%), симптом "низкой подушки" (21,9\%). Цефалгии при АГ II ст., вероятно, носят венозный характер, они обусловлены избыточным кровенаполнением венозных сосудов (вен и венозных синусов) и затруднением венозного оттока, что косвенно подтверждает нарастание "венозных жалоб" при АГ ІІ ст. по сравнению с АГ I ст. $(57,8$ и $13,5 \%$ соответственно; $\mathrm{P}<0,05)$ и объективными данными церебральной гемодинамики в нашем исследовании. Кардиальные жалобы при АГ у подростков встречались в $31,7 \%$ случаев в виде сердцебиения, при АГ II ст. они встречались также чаще, чем при АГ І ст. (16,2 и 57,8\% соответственно; $\mathrm{P}<0,05)$.

У 31 подростков с АГ (37,8\% от общего числа больных) были выявлены начальные признаки недостаточности кровообращения мозга (НПНКМ). Для этого синдрома характерно появление субъективных жалоб (головная боль, головокружение, шум в голове, снижение памяти и работоспособности). Не менее двух из указанных жалоб отмечались еженедельно в течение не менее трех последних месяцев.

В нашем исследовании НПНКМ были зарегистрированы у 5 подростков $(13,5 \%)$ с АГ I ст. и у 26 человек $(57,8 \%)$ при АГ II ст. Увеличение среди подростков с АГ НПНКМ при АГ II ст. статистически значимо $(\mathrm{P}<0,05)$ по сравнению с АГ І ст.

Наличие НПНКМ при АГ у подростков в возрасте от 15 до 17 лет достигало 71,6\%. При оценке наличия и выраженности неврологических нарушений при АГ у подростков был обнаружен псевдобульбарный синдром, в контрольной группе этот синдром не встречался. Псевдобульбарный синдром был выявлен при АГ ІІ ст. в 8,1\% случаев в виде различной выраженности дизартрии, рефлексов орального автоматизма, оживления рефлексов с задней стенки глотки и мягкого неба. Псевдобульбарный синдром у детей с АГ является преморбидным состоянием - следствием неблагоприятных воздействий внутриутробного и неонатального периодов, фактором риска развития АГ.

Оценка церебральной гемодинамики у подростков с АГ, выполненная с помощью допплерографии, показала, что у подростков с АГ I ст. артерии характеризовались отсутствием изменений траектории хода общей сонной артерии (ОСА), внутренней сонной артерии ВСА (BCA) и симметричностью. Толщина комплекса интима-медиа (ТКИМ) у подростков с АГ не была изменена (рис. 1).

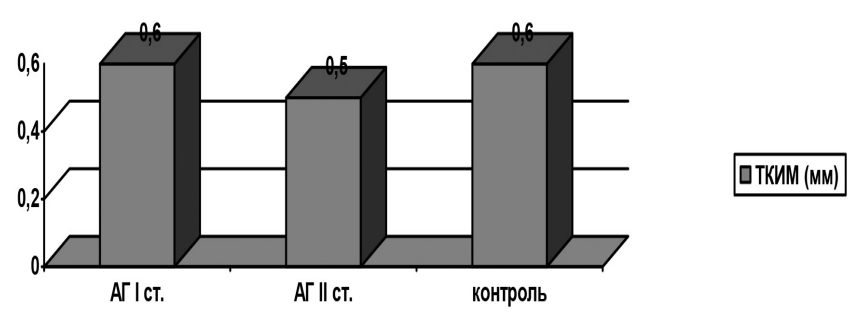

Рис. 1. Показатели толщины комплекса интима-медиа у подростков с АГ 
В то же самое время кровоток был изменен у детей с АГ І ст. по сравнению с контрольной группой: имелись признаки умеренной симпатикотонии, характеризующейся увеличением объемных скоростей в ОСА, позво- ночной артерии (ПА) (Р<0,05), а также умеренным увеличением линейных скоростей кровотока V max и V mean, без статистически значимых изменений IR, PI в CMA (табл.).

Таблица

\section{Сравнительный анализ показателей кровотока при АГ I и II ст. у подростков}

\begin{tabular}{|c|c|c|c|}
\hline Показатели & АГ І ст. $(\mathrm{n}=37)$ & АГ II ст. $(n=45)$ & Контроль $(\Pi=30)$ \\
\hline \multicolumn{4}{|c|}{$\mathrm{OCA}$} \\
\hline $\mathrm{V}$ mean $(\mathrm{cm} / \mathrm{c})$ & $47,3 \pm 12,72$ & $50,7 \pm 14,10$ & $46,6 \pm 12,4$ \\
\hline $\mathrm{V} \max (\mathrm{cm} / \mathrm{c})$ & $136,4 \pm 32,30^{*}$ & $137,4 \pm 23,26^{*}$ & $109,1 \pm 28,61$ \\
\hline $\mathrm{V} \min (\mathrm{cm} / \mathrm{c})$ & $23,3 \pm 6,10$ & $26,9 \pm 9,96$ & $26,6 \pm 9,16$ \\
\hline IR & $0,8 \pm 0,14^{*}$ & $0,8 \pm 0,09^{*}$ & $0,7 \pm 0,05$ \\
\hline PI & $2,3 \pm 0,64^{*}$ & $2,1 \pm 0,46^{*}$ & $1,7 \pm 0,44$ \\
\hline V об. ср. (мл/мин) & $344,0 \pm 0,13$ & $340,7 \pm 61,44$ & $298,8 \pm 96,78$ \\
\hline V об. $\max$ (мл/мин) & $1043,9 \pm 217,16^{*}$ & $970,6 \pm 297,61$ & $788,3 \pm 203,16$ \\
\hline V об. $\min ($ мл/мин) & $117,4 \pm 58,77$ & $119,5 \pm 62,76$ & $132,2 \pm 45,89$ \\
\hline \multicolumn{4}{|l|}{$\mathrm{BCA}$} \\
\hline $\mathrm{V}$ mean $(\mathrm{cm} / \mathrm{c})$ & $44,8 \pm 7,61$ & $46,1 \pm 9,52$ & $42,4 \pm 9,10$ \\
\hline $\mathrm{V} \max (\mathrm{cm} / \mathrm{c})$ & $88,0 \pm 16,92$ & $96,3 \pm 29,38$ & $76,5 \pm 17,54$ \\
\hline $\mathrm{V} \min (\mathrm{cm} / \mathrm{c})$ & $30,8 \pm 5,90$ & $29,3 \pm 7,76$ & $31,9 \pm 7,68$ \\
\hline IR & $0,7 \pm 0,19$ & $0,7 \pm 0,35^{*}$ & $0,6 \pm 0,06$ \\
\hline PI & $1,2 \pm 0,30^{*}$ & $1,4 \pm 0,51 *$ & $1,1 \pm 0,19$ \\
\hline V об. ср. (мл/мин) & $242,3 \pm 53,98$ & $235,2 \pm 65,51$ & $237,6 \pm 77,41$ \\
\hline V об. $\max$ (мл/мин) & $462,1 \pm 157,59$ & $441,9 \pm 177,65$ & $379,8 \pm 99,54$ \\
\hline $\mathrm{V}$ об. $\min ($ мл/мин) & $145,0 \pm 53,91$ & $148,2 \pm 95,82$ & $125,3 \pm 35,91$ \\
\hline \multicolumn{4}{|c|}{ ПА } \\
\hline $\mathrm{V}$ mean $(\mathrm{cm} / \mathrm{c})$ & $35,1 \pm 9,53$ & $33,9 \pm 9,99$ & $29,2 \pm 8,97$ \\
\hline $\mathrm{V} \max (\mathrm{cm} / \mathrm{c})$ & $69,0 \pm 17,39$ & $72,0 \pm 21,15$ & $57,5 \pm 13,43$ \\
\hline $\mathrm{V} \min (\mathrm{cm} / \mathrm{c})$ & $21,2 \pm 7,09$ & $20,7 \pm 6,32$ & $17,8 \pm 6,10$ \\
\hline IR & $0,7 \pm 0,08$ & $0,7 \pm 0,08$ & $0,7 \pm 0,05$ \\
\hline PI & $1,4 \pm 0,46$ & $1,5 \pm 0,40$ & $1,4 \pm 0,22$ \\
\hline V об. ср. (мл/мин) & $85,8 \pm 42,37 *$ & $75,3 \pm 47,38^{*}$ & $56,9 \pm 21,80$ \\
\hline V об. $\max$ (мл/мин) & $163,8 \pm 87,60$ & $140,6 \pm 79,02$ & $119,7 \pm 53,98$ \\
\hline V об. $\min ($ мл/мин) & $40,6 \pm 30,09$ & $35,3 \pm 28,18$ & $27,0 \pm 15,53$ \\
\hline
\end{tabular}

У подростков с АГ имело место нарастание изменений в гемодинамике артериального и венозного русла от АГ І ст. к АГ II ст. Признаки симпатикотонии артериального русла возрастали при АГ ІІ ст.

Венозный интра- и экстракраниальный кровоток у подростков с АГ І ст. не был изменен. У подростков с АГ ІІ ст. венозный интра- и экстракраниальный кровоток характеризовался статистически значимым увеличением объемных скоростей в общей яремной вене (ОЯВ) (V об. $\max , \mathrm{V}$ об. min) по сравнению с контрольной группой, что, вероятно, связано с открытием коллатерапей "оттока" (лицевая вена, поверхностные вены), минующих внутреннюю яремную вену (ВЯВ), - компенсаторное повышение (рис. 2).

Таким образом, полученные данные подтверждают предположение о сохранности механизмов ауторегуляции церебральной гемодинамики у детей и подростков с АГ І ст. и говорит о первичном вовлечении в процесс артерий при АГ у детей, в отличие от взрослых, где 


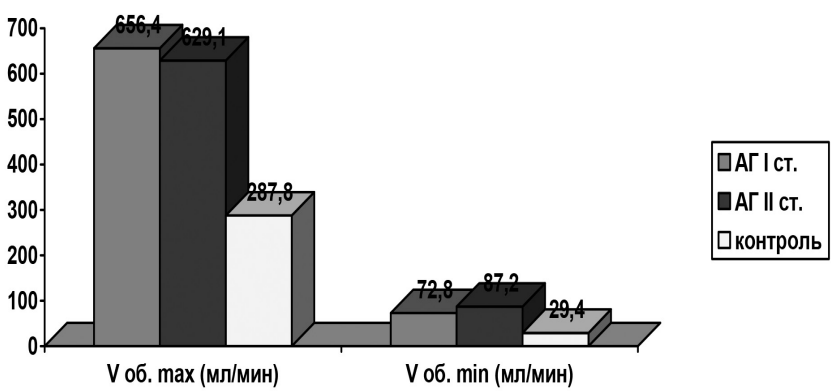

Рис. 2. Основные показатели кровотока в ОЯВ при АГ I и ІІ ст. у подростков

первично или параллельно с артериями в патологический процесс вовлекаются вены $[2,7]$.

Выводы: Таким образом, в клинической

\section{СПИСОК ЛИТЕРАТУРЫ}

1. Александров, А. А. Профилактика артериальной гипертензии с детства: подходы, проблемы, перспективы // Кардиоваскулярная терапия и профилактика. - 2004. - № 3, ч. II. - C. 5-9.

2. Андреева И. Г., Мишина Е. Г. Возрастные изменения кровоснабжения головного мозга у детей и подростков 11-17 лет // Экология человека. - 2005. - № 3. C. 34-37.

3. Батурова Е. А. Ультразвуковая допплеровская диагностика венозной дисгемии у детей школьного возраста с диагнозом вегетососудистой дистонии в условиях поликлиники // Российский педиатрический журнал. 2000. - № 1. - С. 8-12.

4. Беляева Л. М., Хрусталева Е. К. Функциональные заболевания сердечно-сосудистой системы у детей. Минск : Амалфея, 2000. - 208 с.

5. Варакип Ю. Я. Эпидемиология сосудистых заболеваний головного мозга // Очерки ангионеврологии: под ред. 3. А. Суслиной. - М.: Атмосфера, 2005. - С. 6683.

6. Леонтьева И. В. Проблема артериальной гипертензии у детей и подростков / И. В. Леонтьева // Российский вестник перинатологии и педиатрии. - 2006. -№ 5. - С. 7-18.

7. Машин, В. В. Неврологические и нейропсихологи- картине АГ у подростков имеют место симптомы, свидетельствующие о венозной церебральной недостаточности, более выраженные при АГ II степени. У 37,8\% подростков при АГ был выявлен синдром начальных проявлений недостаточности кровоснабжения мозга со статистически значимым увеличением при АГ II степени. Нарушение церебральной артериальной и венозной гемодинамики у подростков нарастает от АГ І степени к АГ II степени и характеризуется увеличением объемного кровотока в венозном русле и линейной скорости кровотока в артериальном русле.

ческие синдромы при гипертонической энцефалопатии. Прогностические критерии : дис. . Д-ра мед. наук / В. В. Машин. М., 2003. - 287 с.

8. Машин В.В. Церебральная дисциркуляция при артериальной гипертонии (клинико-ультразвуковое исследование) / В. В. Машин, Л. А. Белова, В. Г. Белов, Е. А. Салихова и др.// Клиническая физиология кровообращения. - 2009. - № 1. - С. 40-44.

9. Салихова Е.А., Машин В.В., Чубарова С.П. Факторы риска развития артериальной гипертензии у подростков // 43-я научно-практическая межрегиональная конференция врачей "Актуальные вопросы здравоохранения. Проблемы, поиски, решения". - Ульяновск, 2008. - C. 242-243.

10. Царегородцева, Л. В. Артериальная гипертония у детей и подростков // Качество жизни. - 2006. - № 3. - С. 32-37.

11. Flynn, J.T. What's New in Pediatric Hypertension // J. Hypertens. - 2001. - № 3. - P. 503-510.

12. Lima E. M. Assessment of risk factors associated with elevated blood pressure in children and adolescents // J. Pediat. - 2004. - Vol. 80, № 1. - P. 3-4.

13. Task force 1: The changing profile of congenital heart disease in adult life / C. A. Warnes et al. // J. Am. Coll Cardiol. - 2001. - Vol. 37. - P. 11701175. 


\title{
SUMMARY
}

\section{TYPICAL MANIFESTATIONS OF VENOUS DYSCIRCULATION IN CHILDREN AND ADOLESCENTS WITH ARTERIAL HYPERTENSION}

\author{
Alidzhanova D.A, Madjidova Yo.N, Tursunkhudjaeva S.Sh. \\ Tashkent Pediatric Medical Institute, Tashkent, Uzbekistan
}

This article is based on data from the survey of 82 adolescents with hypertension. Age of surveyed varied from 12 to 17 years, mean age was $14.5 \pm 1.2$ years. According to the study, venous dyscirculation in adolescents with cerebral arterial hypertension is characterized by specific set of clinical symptoms. The presence of symptoms was indicative for cerebral venous insufficiency, allowing us to refine the diagnosis and the extent of the disease and to appoint a pathogenetically substantiated therapy.

Key words: venous dyscirculation, hypertension, adolescents, diagnosis

\section{XÜLASə}

\section{ARTERİAL HİPERTONIYASI OLAN UŞAQ VӘ YENIYETMӘLӘRDӘ VENOZ DISSSIRKULYASIYYANIN XARAKTER OLAMOTLORİ}

\author{
Alicanova D.A., Məcidova E.N., Tursunxocayeva S.Ş. \\ Daşkənd pediatrik tibb institutu, Daşkənd, Özbəkistan
}

Təqdim edilmiş məqalədə arterial hipertenziyadan əziyyət çəkən 82 uşaq və yeniyetmələrin müayinəsi araşdı-

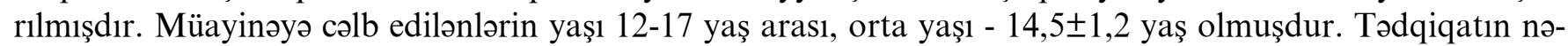
ticələrinə görə, arterial hipertenziya zamanı yeniyetmələrdə baş beyinin venoz dissirkulyasiyası müəyyən kliniki simptomokomplekslə xarakterizə olunur. Serebrovaskulyar venoz çatmamazlığa dəlalət edən simptomların olması diaqnozu və xəstəliyin dərəcəsini dəqiqləşdirməyə, həm də patogenetik əsaslanmış müalicəni təyin etməyə kömək edir.

Açar sözlər: venoz dissirkulyasiya, arterialhipertoniya, yeniyetmələr, diaqnostika

Redaksiyaya daxil olub: 17.06.2015

Çapa tövsiyə olunub: 03.07.2015

Rəyçi: prof. Şiraliyev R.K. 